\title{
Resistin, insulin sensitivity and markers of inflammation in a cohort of Romanian patients under combined antiretroviral therapy
}

\author{
Cătălin Tilişcan 1,2*, Victoria Aramă ${ }^{1,2}$, Raluca Mihăilescu', Daniela Munteanu', Mihaela Rădulescu 1,2, \\ Adriana Hristea ${ }^{1,2}$, Cristina Popescu ${ }^{1,2}$, Ana Maria Tudor ${ }^{1,2}$, Mihai Lazăr ${ }^{1,2}$, Roxana Petre ${ }^{1}$, Adrian Streinu-Cercel ${ }^{1,2}$, \\ Daniela Adriana Ion², Sorin Ștefan Aramă \\ From The 10th Edition of the Scientific Days of the National Institute for Infectious Diseases "Prof Dr Matei \\ Bals" \\ Bucharest, Romania. 15-17 October 2014
}

\section{Background}

Several authors have recently reported that resistin, a novel adipokine, may be associated with insulin resistance in HIV patients. Our objective was to evaluate resistin dysfunction in correlation with insulin sensitivity, lipid abnormalities and markers of inflammation in a cohort of adult HIV infected patients who were under complex combined therapy (cART).

\section{Methods}

We performed a transversal study that used the following inclusion criteria: non-diabetic patients with documented HIV infection, undergoing stable cART for at least 6 months. Clinical, metabolic, inflammatory and immuno-virological patterns were assessed (age, sex, body mass index, HIV load, actual and nadir CD4, duration of HIV infection and antiretroviral therapy, lipid panel, C-reactive protein - CRP). Resistin levels were evaluated using KAPME Biosource EASIA. In order to test the sensitivity to insulin we used the QUICKI index, the best surrogate marker after glucose clamp index. Parametric and non-parametric variables were described using means $( \pm$ Standard Deviation - SD) and medians (Interquartile Ratio - IQR), respectively.

\section{Results}

We enrolled 94 patients ( $56.4 \%$ males, $43.6 \%$ females), with a mean age of $31.9( \pm 13.5)$ years. The median time

\footnotetext{
* Correspondence: catalin_tiliscan@yahoo.com

"National Institute for Infectious Diseases "Prof. Dr. Matei Balş", Bucharest, Romania

Full list of author information is available at the end of the article
}

from HIV diagnostic was 63 (74) months; the median time of treatment was 60 (50) months. More than half of patients $(72.3 \%)$ had undetectable HIV load and the median CD4 count was $492(419) / \mathrm{cmm}$. The mean level of resistin was $6( \pm 2.6) \mathrm{ng} / \mathrm{mL}$. The most frequent resistin dysfunction, after adjusting the results by sex and age, was hyporesistinemia (40.2\%); hyperresistinemia was less frequent (17.4\%). Most patients had insulin resistance (66.3\%), based on QUICKI levels below the cut-off point of 0.33. We found no relation between QUICKI values and resistin, in a linear regression model $(\mathrm{R}=0.054, \mathrm{p}=$ 0.614 ) or correlation between the presence of insulin resistance and resistin dysfunction $(\mathrm{p}=0.320)$. Lipid metabolism abnormalities were not influenced by resistin dysfunction. Resistin serum values were positively correlated with the levels of CRP $(\mathrm{R}=0.21, \mathrm{p}=0.05)$.

\section{Conclusion}

In our cohort of young HIV infected patients, insulin resistance was not mediated by resistin dysfunction, contrary to recent reports, but may contribute to an increased inflammatory profile.

\section{Acknowledgement \\ This paper is supported by the Sectoral Operational Programme Human Resources Development (SOP HRD), financed from the European Social Fund and by the Romanian Government under the contract numbers POSDRU/ 159/1.5/S/137390.}

\section{Authors' details}

1National Institute for Infectious Diseases "Prof. Dr. Matei Balş", Bucharest, Romania. ${ }^{2}$ Carol Davila University of Medicine and Pharmacy, Bucharest, Romania. 
Submit your next manuscript to BioMed Central and take full advantage of:

- Convenient online submission

- Thorough peer review

- No space constraints or color figure charges

- Immediate publication on acceptance

- Inclusion in PubMed, CAS, Scopus and Google Scholar

- Research which is freely available for redistribution

Submit your manuscript at www.biomedcentral.com/submit
C Biomed Central 